\title{
STUDYING THE STRUCTURE AND PROPERTIES OF THE MATERIAL OF THE NODES A HONEYCOMB STRUCTURE AFTER DIFFUSION ALUMINIZING
}

\author{
N. B. Pugacheva ${ }^{1}$, L. M. Zamaraev ${ }^{1}$, A. S. Igumnov ${ }^{2}$ \\ ${ }^{1}$ Institute of Engineering Science, Ural Branch of the Russian Academy of Sciences, 620049, 34 Komsomolskaya st., \\ Ekaterinburg, Russian Federation \\ ${ }^{2}$ Institute of Mathematics and Mechanics, Ural Branch of the Russian Academy of Sciences, 620990, \\ 16 S. Kovalevkoy st., Ekaterinburg, Russian Federation
}

*Corresponding author. E-mail: nat@imach.uran.ru ; address for correspondence: ul. Komsomolskaya 34, 620049, Ekaterinburg, Russian Federation. Tel.:+7 343 3753591; fax: +7 3433745330

The paper presents results of studying the structure and properties of the material of the interfaces of a honeycomb structure after diffusion aluminizing. The structure is tightly rolled straight and corrugated $\mathrm{Cr} 15 \mathrm{Al} 5$ alloy tapes, $55 \mu \mathrm{m}$ thick, with a $2 \mathrm{~mm}$ thick outer jacket made of steel $12 \mathrm{Cr} 18 \mathrm{Ni10Ti}$. It is shown that, after aluminizing, the content of aluminum increases regularly through the tape thickness. It preserves the ferrite structure, in which there appear ordering domains of the B2-phase. The values of the temperature linear expansion coefficient for aluminized Cr15A15 alloy and 12Cr18Ni10Ti steel samples have been obtained. The distributions of stresses in the nodes of the honeycomb structure arising at heating up to $600{ }^{\circ} \mathrm{C}$ and $900{ }^{\circ} \mathrm{C}$ have been obtained by the results of calculation on triangular finite element meshes in the elastic region. The stresses arising at heating in the majority of the nodes are shown to be compressive, the maximal tensile stresses being small.

Keywords: honeycomb structure, corrugated tape, steel, alloy, aluminide, diffusion welding, stress, strain, elastic modulus, finite element method.

DOI: $10.17804 / 2410-9908.2016 .4 .071-088$

\section{References}

1. Naoto Y. An addition agent effect on the high-temperatures oxidation resistance of the foil, made of ferritic stainless steel, applied as a metallic catalyst support. Dzaire to Purosesu (Curr. Adv. Mater. and Proc.), 1991, vol. 4, no. 6, pp. 1772-1775. (In Russian).

2. Mikio Y. Development of the heat-resistant steel foil, applied as a metallic support. Dzaire to Purosesu (Curr. Adv. Mater. and Proc.), 1991, vol. 4, no. 6, pp. 1784-1787. (In Russian).

3. Kositsyn S.V., Korol'kov V.V., Tesla V.I., Vladimirov A.N., Pugacheva N.B. Increase in thermal stability of metallic monolith supports for catalysts by gas-phase calorizing. Kinetics and Catalysis, 1998, vol. 39, iss. 5, pp. 649-654.

4. Kornilov I.I. Zheleznye splavy. Splavy zhelezo-khrom-aluminiy [Iron Alloys. IronChromium-Aluminum Alloys]. M.; L., Izd-vo AN SSSR Publ., 1945, 416 p. (In Russian).

5. Zhukov L.P., Plemyannikova I.M., Mironova M.N., Barkaya D.S., Shumkov U.V. Splavy dlya nagrevateley [Alloys for Heaters]. M., Metallurgiya Publ., 1985, 144 p. (In Russian).

6. Mrowiec S., Werber J. Sovremennye zharostoikie materialy: spravoch. izd. [Modern Heat Resistant Materials: reference book, transl., ed. S.B. Maslenkova]. M., Metallurgiya Publ., 1986, 360 p. (In Russian).

7. Pugacheva N.B., Ekzemplyarova E.O., Zadvorkin S.M. Effect of aluminium on the structure and physical properties of Fe-Cr-Al alloys. Russian Metallurgy (Metally), 2006, no. 1, pp. 61-68. DOI: $10.1134 / \mathrm{S} 0036029506010113$.

8. Oliver W.C., Phar G.M. An improved technique for determining hardness and elastic modulus using load and displacement sensing indentation experiments. Journals of Materials Research, 1992, vol. 7, iss. 06, pp. 1564-1583. DOI: 10.1557/JMR.1992.1564. 
9. Golovin Yu.I., Ivolgin V.I., Korenkov V.V. Determination of a complex of mechanical properties of nanomaterials by nanoindentation. Kondensirovannye sredy i mezhfaznye granitsy, 2001, vol. 3, no. 2, pp. 122-135. (In Russian).

10. Bulychev S.I., Alekhin V.P. Determination of yield strength from the actual contact area of a spherical indenter in nano-, micro- and macroindentation. Deformatsiya $i$ razrushenie materialov, 2007, no. 1, pp. 30-37. (In Russian).

11. Guzanov B.N., Kositsyn S.V., Pugacheva N.B. Uprochnyayushchie zashchitnye pokrytiya v mashinostroenii [Strengthening Protective Coatings in Mechanical Engineering]. Ekaterinburg, UrO RAN Publ., 2004, 244 p. (In Russian).

12. Kolachev B.A., Ilyin A.A. Drozdov P.D. Composition, structure and mechanical properties of binary intermetallics. Izvestiya Vuzov. Tsvetnaya metallurgiya, 1997, no. 6, pp. 41-52. (In Russian).

13. Pugacheva N.B. The structure and properties of alloys and coatings with an ordered $\beta$-phase following heat treatment. Metal Science and Heat Treatment, 2007, iss. 5, pp. 240-247. DOI: $10.1007 / \mathrm{s} 11041-007-0043-4$.

14. Smirnov S.V., Pugacheva N.B., Tropotov A.V., Soloshenko A.N. Resistance to deformation of structural constituents of a high-alloy brass. Physics of Metals and Metallography, 2001, vol. 91, no. 2, pp. 210-215.

15. Smirnov S.V., Pugacheva N.B., Soloshenko A.N., Tropotov A.V. Plastic deformation of a high-alloy brass. Physics of Metals and Metallography, 2002, vol. 93, no. 6, pp. 584-593.

16. Smirnov S.V., Pugacheva N.B., Myasnikova M.V., Matafonov P.P., Polkovnikov T.V. Micromechanics of fracture and deformation of brass. Fizicheskaya mezomekhanika, 2004, no. 7, part 1, pp. 165-168. (In Russian).

17. Kolmogorov V.L. Mekhanika obrabotki metallov davleniem [Mechanics of Metal Forming]. M, Metallurgiya Publ., 688 p. (In Russian).

18. Klyuch staley. Izgotovlenie i postavka: spravochnik [Key to Steels. Production and Delivery: reference book, trans. Germ.]. M., Intermet Inzhiniring Publ., 2001, 734 p. (In Russian).

19. Stali i splavy. Marochnik: sprav. izd. [Steels and Alloys. Grade Guide, eds. V.G. Sorokin, M.A. Gervasiev]. M., Intermet Inzhiniring Publ., 2003, 608 p. (in Russian). 
Подана в журнал: 17.08.2016

УДК 546.3: 620. 170

DOI: $10.17804 / 2410-9908.2016 .4 .071-088$

\title{
ИССЛЕДОВАНИЕ СТРУКТУРЫ И СВОЙСТВ МАТЕРИАЛА УЗЛОВ СОТОВОЙ КОНСТРУКЦИИ ПОСЛЕ ДИФФУЗИОННОГО АЛИТИРОВАНИЯ
}

\author{
Н. Б. Пугачева ${ }^{1}$, Л .М. Замараев ${ }^{1}$, А. С. Игумнов ${ }^{2}$ \\ ${ }^{1}$ Федеральное государственное бюджетное учреждение науки Институт машиноведения Уральского \\ отделения Российской академии наук, ул. Комсомольская, 34, Екатеринбург, Российская Федерация \\ ${ }^{2}$ Федеральное государственное бюджетное учреждение науки Институт математики и механики \\ имени Н.Н. Красовского Уральского отделения Российской академии наук, \\ ул. С. Ковалевской, 16, Екатеринбург, Российская Федерациия
}

*Ответственный автор. Электронная почта: nat@imach.uran.ru; адрес для переписки: ул. Комсомольская, 34, 620049, Екатеринбург, Российская Федерация. Телефон: +7 (343) 375-35-91; факс: +7 (343) 374-53-30

В работе представлены результаты исследований структуры и свойств материала узлов сопряжения сотовой конструкции после диффузионного алитирования. Конструкция представляет собой плотно свернутые прямую и гофрированную ленты из сплава Х15Ю5 толщиной 55 мкм с наружным кожухом из стали 12 Х18Н10Т толщиной 2 мм. Показано, что после алитирования содержание алюминия увеличивается равномерно по всей толщине ленты. При этом в ней сохраняется ферритная структура, в которой появляются домены упорядочения В2-фазы. Получены значения коэффициента температурного линейного расширения для образцов сплава Х15Ю5 и стали 12X18Н10Т после алитирования. По результатам расчета на сетках треугольных конечных элементов в упругой области получены распределения напряжений в узлах сотовой конструкции, возникающих при нагревах до 600 и $900{ }^{\circ} \mathrm{C}$. Показано, что возникающие при нагреве напряжения в большинстве узлов являются сжимающими, а максимальные растягивающие напряжения малы.

Ключевые слова: сотовая конструкиия, гофрированная лента, фехраль, сталь, сплав, диффузионная сварка, напряжения, модуль упругости, метод конечных элементов.

\section{1. Введение}

Металлические сотовые конструкции с многочисленными узкими каналами часто используются в качестве носителя катализаторов химических реакций, за счет протекания которых проводят очистку газов или жидкостей от вредных примесей [1-3]. Веществакатализаторы традиционно наносят в виде тонкого слоя на внутренние поверхности каналов сотовых конструкций. Сами катализаторы не вступают в химическую реакцию, но существенно ускоряют её. К таким веществам относятся металлы платиновой группы, серебро, никель. Примером подобной конструкции является блок носителя катализатора для очистки от вредных примесей выхлопных газов двигателя внутреннего сгорания легковых автомобилей. В результате окислительно-восстановительных реакций токсичные соединения $\mathrm{CO}, \mathrm{CH}$ и $\mathrm{NO}_{x}$, образующиеся при сгорании топлива, окисляются или восстанавливаются до углекислого газа, азота и воды.

Особый интерес в качестве материала для подобных сотовых конструкций представляют сплавы $\mathrm{Fe}-\mathrm{Cr}-\mathrm{Al}$ (фехрали), которые являются самыми жаростойкими среди всех

Pugacheva N. B. et al. / Studying the structure and properties of the material of the nodes a honeycomb structure after diffusion aluminizing 
известных деформируемых сплавов и используются, главным образом, для нагревателей как в промышленном термическом оборудовании, так и в бытовой технике [3-6]. Следует выделить две основные проблемы в создании конструкции металлического носителя: вопервых, разработка экономно легированной технологичной металлической тонкой ленты с высокой жаростойкостью и, во-вторых, разработка эффективной технологии закрепления гофров в блоке (пайки или сварки блока). Обе эти проблемы были достаточно успешно решены в разработке технологии изготовления металлического блока - носителя каталитического нейтрализатора с использованием термодиффузионного алитирования [3, 7]. При эксплуатации подобные сотовые конструкции обычно не испытывают высоких механических нагрузок, действующие циклические напряжения не выходят из упругой области. При этом очень важно представлять, какие термические напряжения возникают в нейтрализаторе при его нагреве и как они могут влиять на прочность закрепления гофров, особенно в узлах, состоящих из материалов разного химического состава и, соответственно, имеющих разные теплофизические свойства.

Цель данной работы - исследование микроструктуры, свойств и определение уровня напряжений, возникающих в узлах сотовой конструкции с неоднородным распределением физико-механических свойств при нагревах по результатам компьютерного моделирования.

\section{2. Материалы и методы исследования}

В качестве объекта исследования выбрана сотовая конструкция, представляющая собой две плотно закрученные в спираль ленты из сплава X15Ю5 толщиной 55 мкм, одна из которых плоская, а вторая - гофрированная треугольного профиля с шагом 1 мм, запрессованные внутрь цилиндрического кожуха из листа нержавеющей стали 12 Х18Н10Т толщиной 1 мм [7]. Наружный диаметр блока 100 мм, высота 90 мм, внешний вид рассматриваемой конструкции представлен на рис. 1. Исследованный блок прошел операцию термодиффузионного алитирования по технологии, подробно описанной в работе [3].

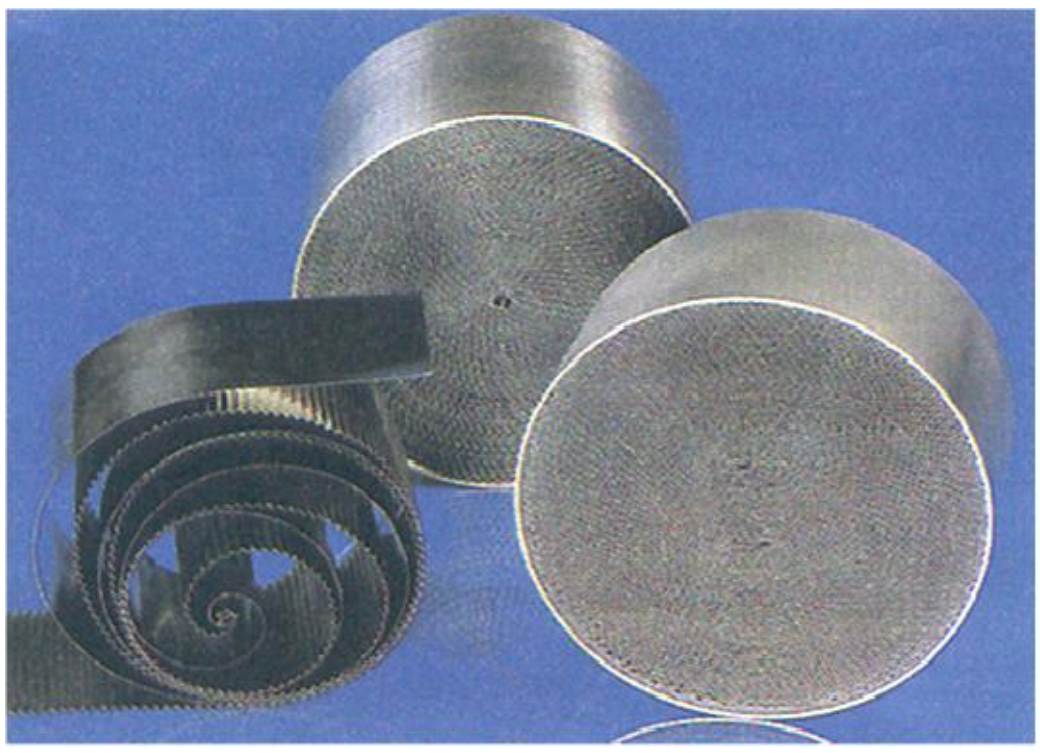

Рис. 1. Внешний вид сотовой конструкции

Pugacheva N. B. et al. / Studying the structure and properties of the material of the nodes a honeycomb structure after diffusion aluminizing 
Металлографические исследования структуры сплавов, из которых изготовлена сотовая конструкция, выполняли на микроскопе Neophot-21, для выявления структуры использовали $10 \%$-й раствор азотной кислоты $\mathrm{HNO}_{3}$. Фазовый состав сплавов и покрытий определяли по результатам рентгеноструктурного анализа фрагментов конструкции, выполненного на дифрактометре ДРОН-2,0 в излучении $\mathrm{Cr}_{\mathrm{K \alpha}}$. Электронно-микроскопические исследования тонких фольг на просвет выполняли с помощью электронного микроскопа JEM-200CX. Фольги готовили механическим утонением образцов до толщины 60-100 мкм и последующей электрополировкой в ортофосфорном, хлорно-уксусном и метаноловом электролитах. Химический состав тонких лент из сплава X15Ю5 и покрытия на стали 12X18Н10T исследовали с помощью микрорентгеноспектрального анализатора Camebax (локальность метода 2 мкм, погрешность - $5 \%$ от измеряемой величины). Дилатометрические испытания выполнены на дилатометре Шевенара с фотозаписью на образцах размерами 2 х 3 х 50 мм.

Определение модуля упругости Е проводили с помощью методики, описанной в работах W.S. Oliver и G.M. Phar [8], С.И. Булычева и В.П. Алехина [9, 10] по результатам анализа диаграммы вдавливания индентора на стадии упругой разгрузки с использованием формулы (1):

$$
E=\frac{1-v^{2}}{\frac{2-\sqrt{A}}{\sqrt{\pi}} \cdot\left(\frac{d h}{d P}-\frac{d h_{t}}{d P}\right)-\frac{1-v_{t}^{2}}{E_{t}}}
$$

где $A$ - площадь проекции отпечатка, мм²; $v, v_{t}, E, E_{t}$ - коэффициенты Пуассона и модули упругости материала образца и индентора соответственно; $\frac{d P}{d h_{c}}-$ жесткость прибора. Значения $v_{t}$ и $E_{t}$ для алмазной пирамиды Виккерса известны [12]: $v_{t}=0,07 ; E_{t}=1141$ ГПа. Площадь поверхности отпечатка находили по формуле (2):

$$
A=4 \cdot h^{2} \cdot \frac{\sin \alpha}{\cos ^{2} \alpha}
$$

где $h$ - глубина отпечатка, мкм; $\alpha$ - половина угла пирамиды Виккерса. Полученные значения модуля упругости для неалитированного сплава X15Ю5 совпадают со справочными данными.

Моделирование термонапряженного состояния сотовой конструкции при нагревах от 20 до 600 и $900{ }^{\circ} \mathrm{C}$ проводили с помощью программного комплекса (ПК) ANSYS. Моделирование нагрева всего фильтра целиком не представляется возможным из-за большого числа составляющих его элементов, поэтому проведено моделирование нагрева 1/32 части фильтра в виде сегмента. Поскольку толщина ленты мала и контакт между лентами осуществлялся только в точках касания их гребней влиянием последующих слоев ленты на тепловые и механические процессы с достаточной степенью достоверности можно пренебречь. Для упрощения поставленной задачи рассматривались только наиболее термически и механически нагруженные элементы конструкции - четыре последних наружных витка ленты и кожух (рис. 2).

Pugacheva N. B. et al. / Studying the structure and properties of the material of the nodes a honeycomb structure after diffusion aluminizing 
Расчет теплового и напряженно-деформированного состояния проводили в упругой области на сетках треугольных конечных элементов (всего 598) (рис. 3).

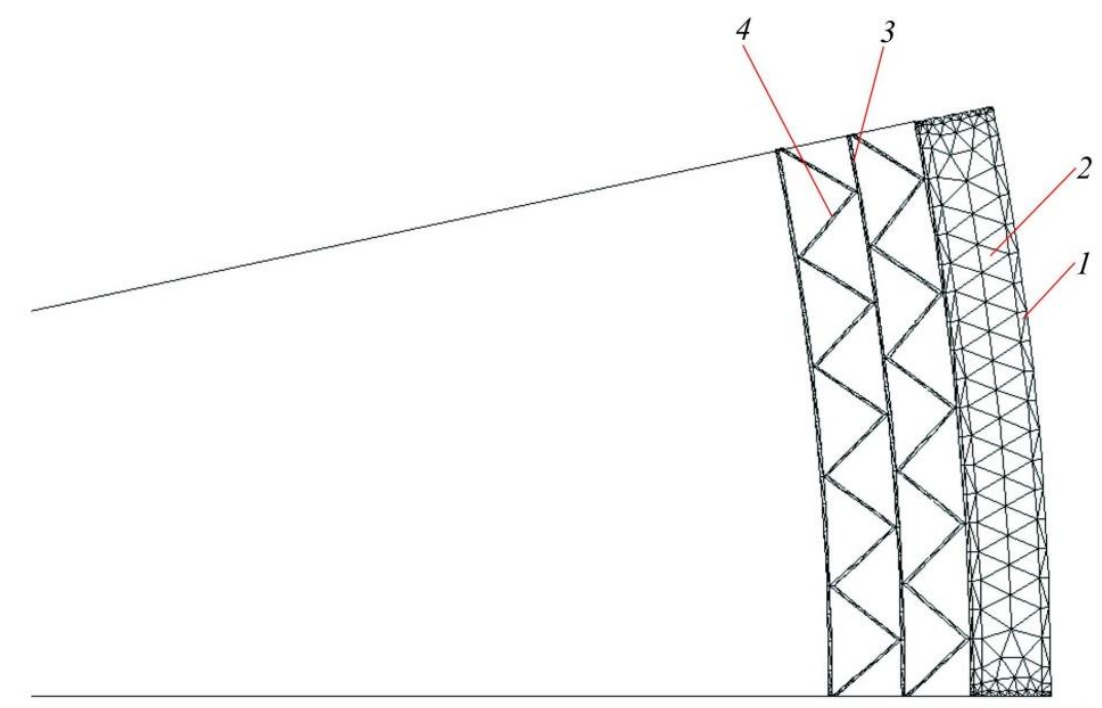

Рис. 2. Схема расчетного элемента блока нейтрализатора:

1 - слой покрытия; 2 - кожух; 3 - плоская лента; 4 - гофрированная лента

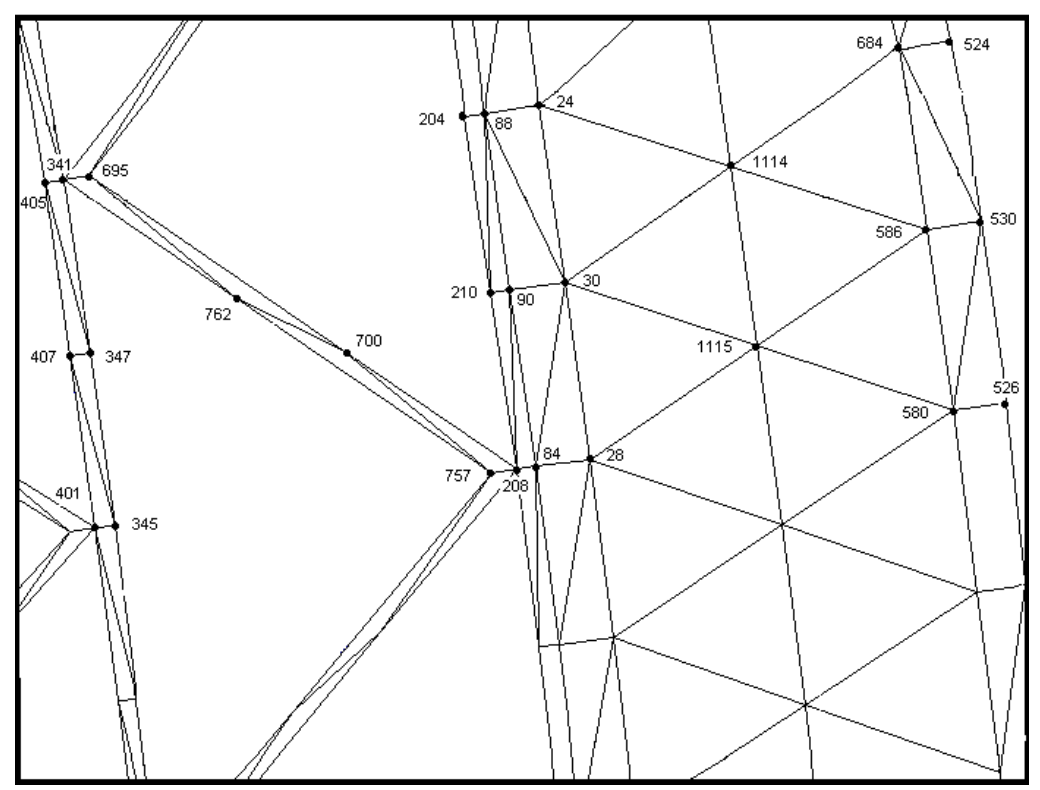

Рисунок 3. Схема и расположения расчётных узлов для моделирования термонапряжённого состояния блока нейтрализатора

На первом этапе расчета решалась тепловая задача нестационарной теплопроводности при граничных условиях третьего рода при температуре окружающей среды $600{ }^{\circ} \mathrm{C}$ и $900{ }^{\circ} \mathrm{C}$ и коэффициенте конвективной теплоотдачи, равном $25 \mathrm{BT} / \mathrm{m}^{2}$ град, характерном для подобных процессов. Теплофизические и упругие свойства покрытия, кожуха, двух слоев плоской и двух слоев гофрированной ленты задавались в узлах сетки в зависимости от температуры нагрева (табл. 1). При этом выбраны значения параметров, полученных как в результате собственных исследований, так и справочные данные $[5,18,19]$.

Pugacheva N. B. et al. / Studying the structure and properties of the material of the nodes a honeycomb structure after diffusion aluminizing 
Таблица 1 - Теплофизические и упругие свойства материалов блока нейтрализатора

\begin{tabular}{|c|c|c|c|c|c|c|c|c|c|c|}
\hline Температура, ${ }^{\circ} \mathrm{C}$ & 20 & 100 & 200 & 300 & 400 & 500 & 600 & 700 & 800 & 900 \\
\hline \multicolumn{11}{|c|}{ Материал покрытия кожуха (интерметаллид FeAl) } \\
\hline$\rho, \kappa \Gamma / \mathrm{M}^{3}$ & 5870 & 5870 & 5870 & 5870 & 5870 & 5870 & 5870 & 5870 & 5870 & 5870 \\
\hline $\mathrm{C}$, Дж/кг ${ }^{\circ} \mathrm{C}$ & 462 & 462 & 496 & 517 & 538 & 550 & 563 & 575 & 596 & 589 \\
\hline$\propto, 10^{-6} 1 /$ град & 14,9 & 14,9 & 15,3 & 15,3 & 15,4 & 15,6 & 15,8 & 16,4 & 16,9 & 17,2 \\
\hline$\lambda, \mathrm{BT} / \mathrm{M}^{\circ} \mathrm{C}$ & 15 & 16 & 18 & 19 & 21 & 23 & 25 & 27 & 26 & 25,6 \\
\hline Е $10^{5}, \mathrm{MПа}$ & 2,6 & 1,94 & 1,89 & 1,81 & 1,74 & 1,66 & 1,57 & 1,47 & 1,35 & 1,18 \\
\hline$\mu$ & 0,285 & 0,29 & 0,297 & 0,303 & 0,310 . & 0,317 & 0,326 & 0,337 & 0,346 & 0,355 \\
\hline \multicolumn{11}{|c|}{ Материал кожуха (сталь 12X18Н10Т) $[5,18,19]$} \\
\hline$\rho, \kappa \Gamma / \mathrm{M}^{3}$ & 7900 & 7900 & 7900 & 7900 & 7900 & 7900 & 7900 & 7900 & 7900 & 7900 \\
\hline $\mathrm{C}$, Дж/кг ${ }^{\circ} \mathrm{C}$ & 462 & 462 & 496 & 517 & 538 & 550 & 563 & 575 & 596 & 598 \\
\hline$\propto, 10^{-6} 1 / г р а д$ & 17,5 & 17,5 & 17,9 & 18 & 18,1 & 18,6 & 19,1 & 19,3 & 19,5 & 19,5 \\
\hline$\lambda, \mathrm{BT} / \mathrm{M}^{\circ} \mathrm{C}$ & 15 & 16 & 18 & 19 & 21 & 23 & 25 & 27 & 26 & 25,6 \\
\hline E $10^{5}, \mathrm{M \Pi а}$ & 1,95 & 1,94 & 1,89 & 1,81 & 1,74 & 1,66 & 1,57 & 1,47 & 1,35 & 1,18 \\
\hline$\mu$ & 0,285 & 0,29 & 0,297 & 0,303 & 0,310 & 0,317 & 0,326 & 0,337 & 0,346 & 0,355 \\
\hline$\sigma_{0,2}, \mathrm{M \Pi а}$ & 315 & - & - & - & - & 205 & 200 & - & - & 156 \\
\hline$\sigma_{\mathrm{B}}, \mathrm{M \Pi а}$ & 650 & - & - & - & - & 440 & 410 & - & - & 220 \\
\hline \multicolumn{11}{|c|}{ Материал ленты (сплав Х17Ю12) } \\
\hline Температура, ${ }^{\circ} \mathrm{C}$ & 20 & 100 & 200 & 300 & 400 & 500 & 600 & 700 & 800 & 900 \\
\hline$\rho, \kappa \Gamma / \mathrm{M}^{3}$ & 6650 & 6650 & 6650 & 6650 & 6650 & 6650 & 6650 & 6650 & 6650 & 6650 \\
\hline $\mathrm{C}$, Дж/кг ${ }^{\circ} \mathrm{C}$ & 480 & 480 & 502 & 558 & 593 & 635 & 985 & 720 & 770 & 800 \\
\hline$\propto, 10^{-6} 1 /$ град & 11,4 & 11,4 & 11,7 & 13 & 13,1 & 13,3 & 13,7 & 14 & 14,3 & 15 \\
\hline$\lambda, \mathrm{BT} / \mathrm{M}^{\circ} \mathrm{C}$ & 13,5 & 15 & 16 & 17 & 18 & 20 & 22 & 24 & 26 & 27 \\
\hline Е $10^{5}, \mathrm{MПа}$ & 1,9 & 1,86 & 1,82 & 1,8 & 1,78 & 1,73 & 1,7 & 1,65 & 1,5 & 1,45 \\
\hline$\mu$ & 0,28 & 0,285 & 0,29 & 0,295 & 0,3 & 0,305 & 0,31 & 0,315 & 0,32 & 0,34 \\
\hline$\sigma_{0,2}$, МПа & 567 & - & - & - & 455 & 415 & 370 & - & - & 55 \\
\hline$\sigma_{\mathrm{B}}$, МПа & 685 & - & - & - & 640 & 500 & 390 & - & 125 & 65 \\
\hline
\end{tabular}

Pugacheva N. B. et al. / Studying the structure and properties of the material of the nodes a honeycomb structure after diffusion aluminizing 
По достижению температуры окружающей среды во всех узлах сетки процесс становится стационарным. Общая длительность расчета составила 7 с. Результатами расчета являлись значения напряжений, возникающих при нагреве в узлах исследуемой сетки. При этом наружная поверхность покрытия кожуха считалась неподвижной, а в каждом узле сетки задавались механические свойства исследуемых материалов (табл. 1) с учетом значений коэффициента линейного термического расширения (табл. 4).

\section{3. Обсуждение результатов}

После термодиффузионного алитирования сотовой конструкции изменяется химический состав гофрированной и плоской тонких лент из сплава X15Ю5. Насыщение алюминием в вакуумной камере при температурах $1000-1100{ }^{\circ} \mathrm{C}$ происходит по механизму низкой активности [11], т.е. за счет преимущественной диффузии железа и хрома в поверхностные слои, что позволяет получать равномерное увеличение содержания этого элемента по всей ее толщине (рис. 4). Следует отметить, что после ХТО увеличение содержания алюминия в ленте не приводит к такому же по значениям уменьшению содержания хрома. Происходит небольшое «разбухание» сплава в ходе насыщения алюминием. Толщина ленты с ростом содержания алюминия увеличивается на $5-7$ мкм. Это создает давление, необходимое для осуществления диффузионной сварки между лентами в сотовой конструкции за счет плотной намотки лент и жесткой фиксации внешним кожухом из стали 12X18Н10Т.

Свойства ленты сплава Х15Ю5 после алитирования отличаются от исходного сплава. Прежде всего увеличение концентрации алюминия неизбежно должно приводить к изменению параметра кристаллической решётки $(a)$, поскольку атомный радиус алюминия суще-

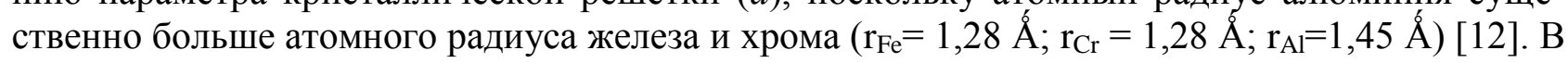
исследованных сплавах параметр решетки меняется незначительно (табл. 2). Причем с увеличением содержания алюминия происходит небольшое уменьшение его значений. Очевидно, это связано с образованием упорядоченной В2-фазы, что подтверждается появлением сверхструктурных линий на рентгенограммах при содержании алюминия в сплаве 8 и более мас. \% (рис. 5). Слабая сверхструктурная линия отмечена даже при 6 мас. \% алюминия в сплаве (рис. 5 a). Как было показано ранее [7, 13], в сплаве $\mathrm{Fe}-\mathrm{Cr}-\mathrm{Al}$ с 8 мас. \% алюминия наблюдали мелкодисперсную (менее 30 нм) доменную структуру (рис. $6 a$ ), причем домены представляют собой упрядоченную по типу CsCl B2-фазу $\mathrm{FeAl}$.

Таблица 2 - Химический состав и свойства лент из сплава Fe-Cr-Al после диффузионного алитирования

\begin{tabular}{|c|c|c|c|c|c|}
\hline \multirow{2}{*}{ № п.п. } & \multicolumn{2}{|c|}{ Содержание, мас. \% } & \multirow{2}{*}{$\begin{array}{c}\text { Толщина } \\
\text { ленты, мкм }\end{array}$} & $a$, нм & $\begin{array}{c}\text { HV 0,05, } \\
\text { МПа }\end{array}$ \\
\cline { 2 - 3 } & $\mathrm{Al}$ & $\mathrm{Cr}$ & 50,4 & 0,288 & 3200 \\
\hline 1 & 5 & 14 & 52,3 & 0,295 & 3800 \\
\hline 2 & 7 & 13 & 53,5 & 0,288 & 4100 \\
\hline 3 & 8 & 13 & 54,2 & 0,289 & 4400 \\
\hline 4 & 9 & 13 & 54,4 & 0,289 & 4800 \\
\hline 5 & 10 & 12,5 & 54,2 & 0,289 & 5200 \\
\hline 6 & 12 & 12,2 & \multicolumn{2}{|c|}{} \\
\hline
\end{tabular}



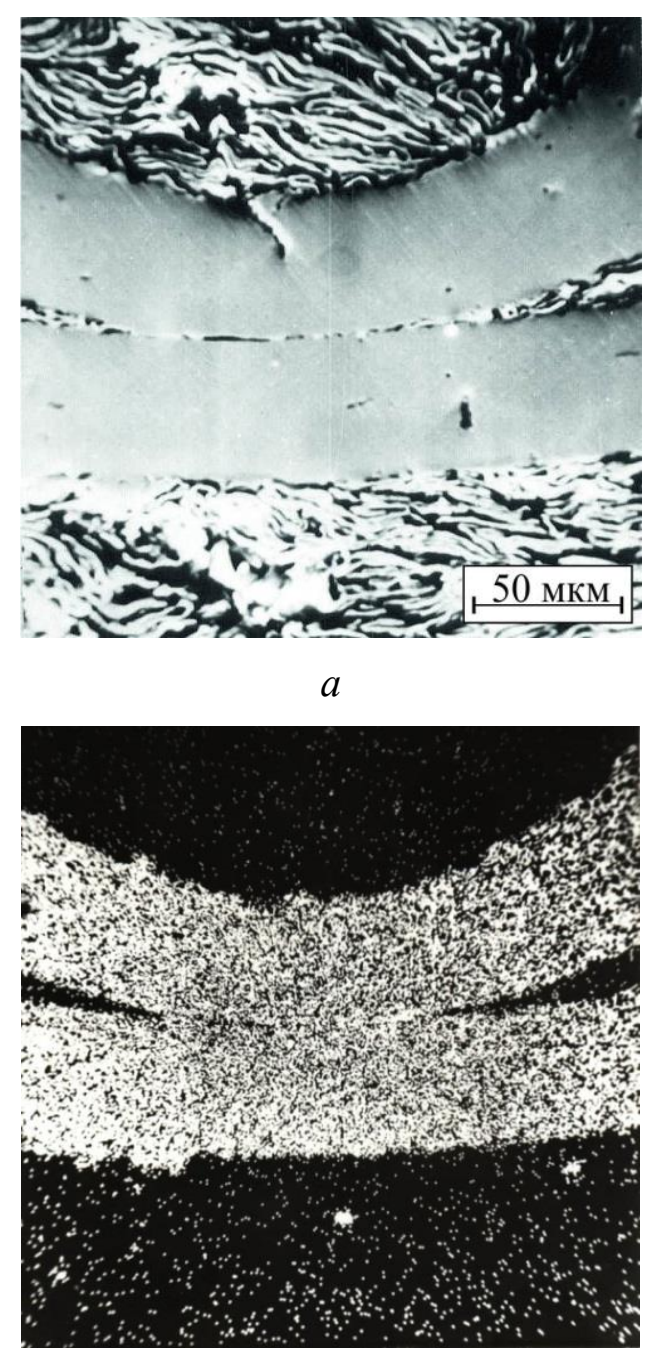

B

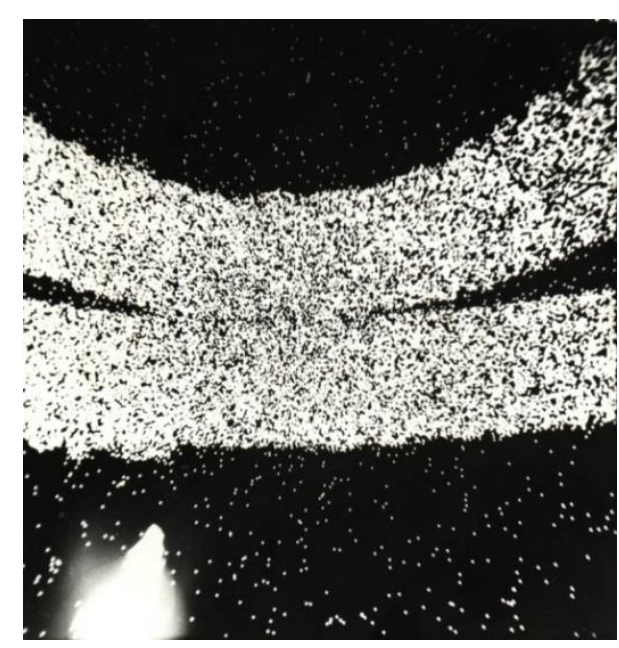

$\sigma$

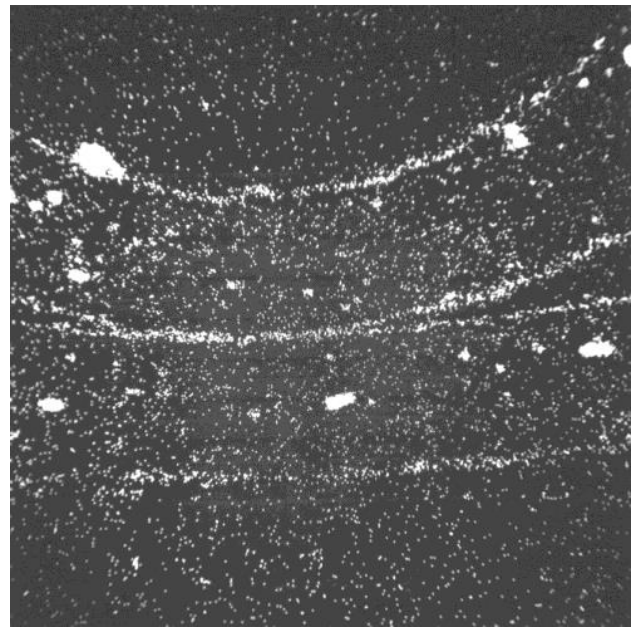

2

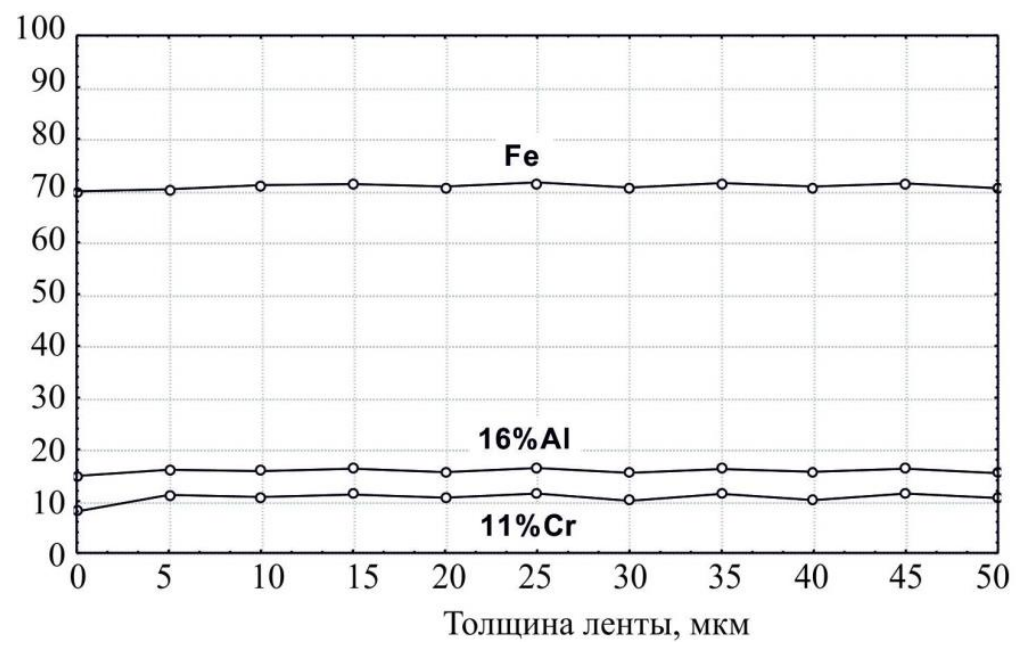

$\partial$

Рис. 4. Распределение элементов по толщине ленты сплава Х15Ю5 после термодиффузионного алитирования: $a$ - микроструктура; $\sigma$ - распределение хрома; $в$ - распределение алюминия; 2 - распределение титана; $\partial$ - зависимости распределения концентрации элементов от толщины ленты

Pugacheva N. B. et al. / Studying the structure and properties of the material of the nodes a honeycomb structure after diffusion aluminizing 


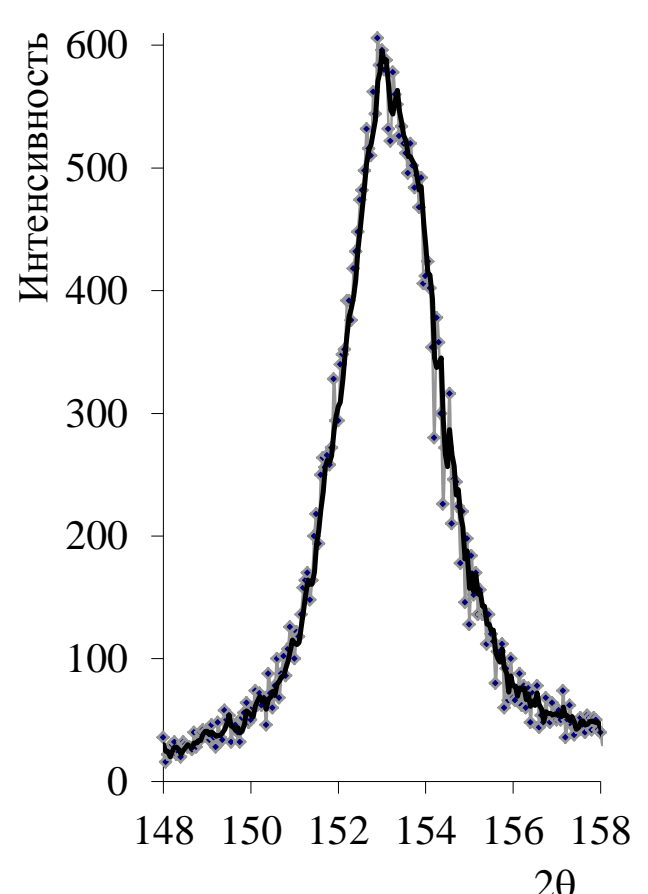

$a$

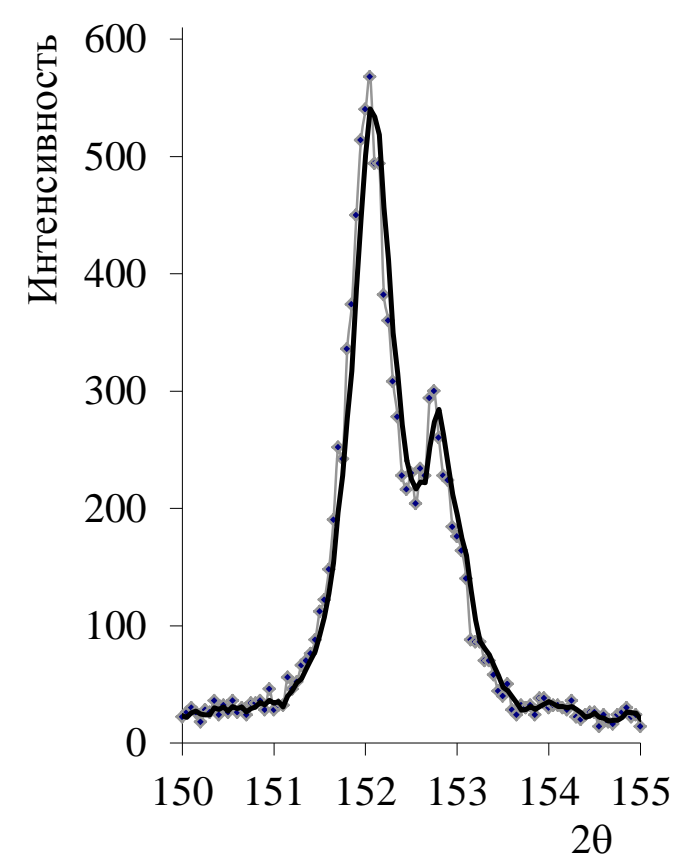

B

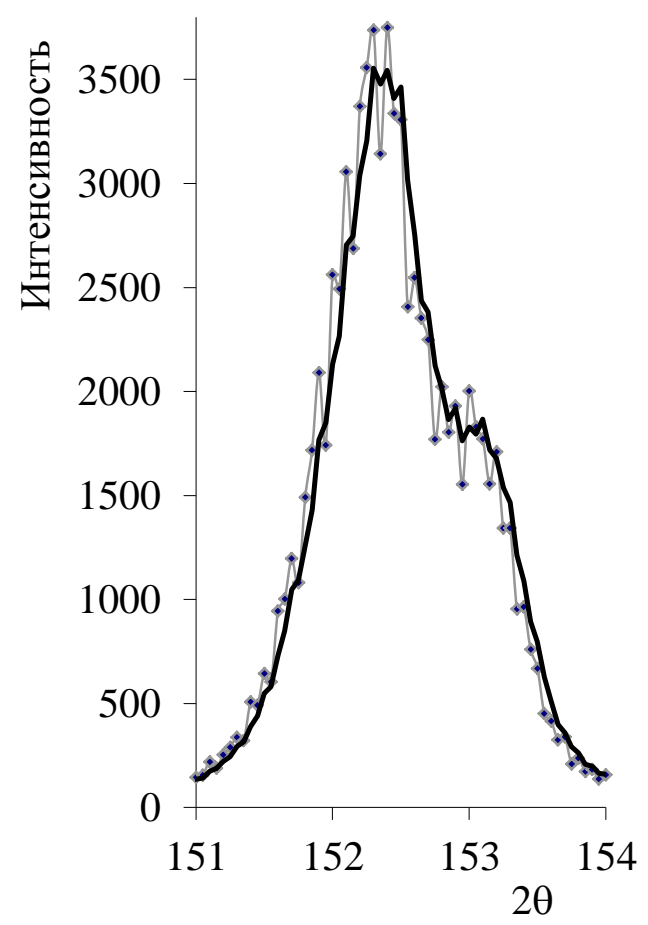

$\sigma$

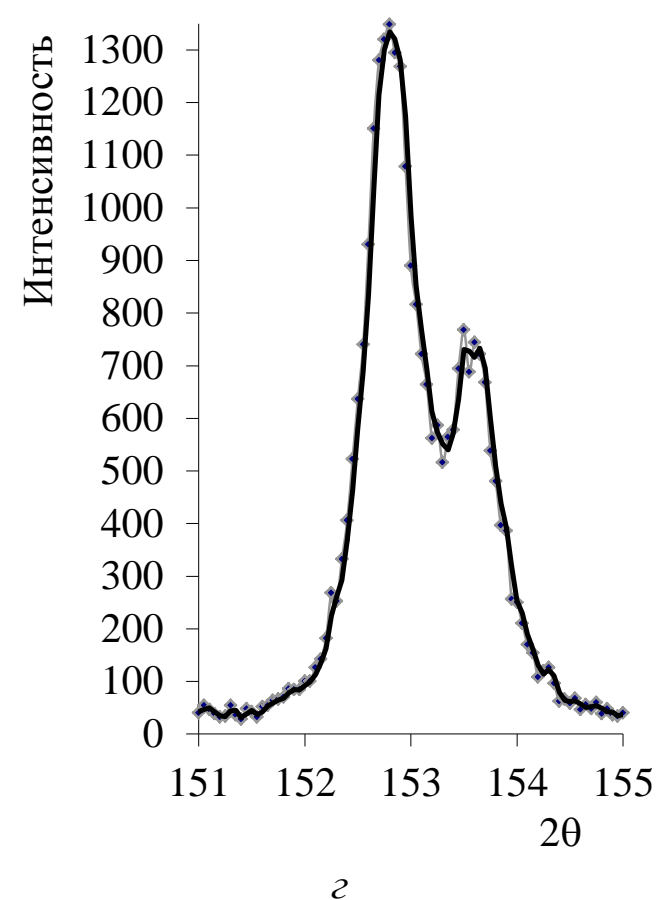

2

Рис. 5. Фрагменты рентгенограмм тонких лент сплавов $\mathrm{Fe}-\mathrm{Cr}-\mathrm{Al}$ (излучение $\mathrm{Cr}$ ): $a$ - в исходном состоянии; $\sigma$ - после алитирования до 6 мас. $\% \mathrm{Al} ; 6-$ до 8 мас. $\% \mathrm{Al}$; г - до 12 мас. \% Al 


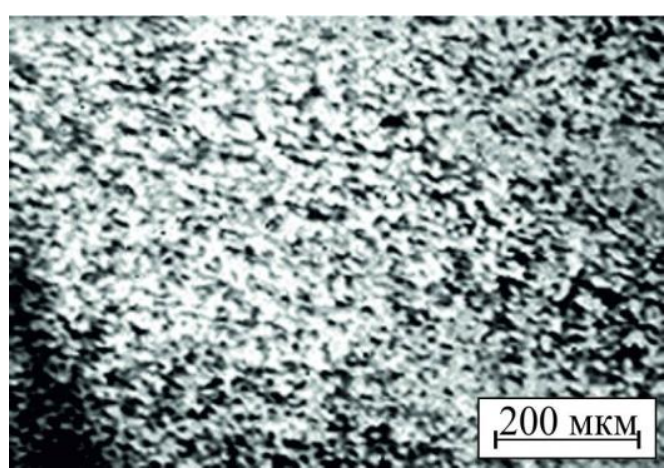

$a$

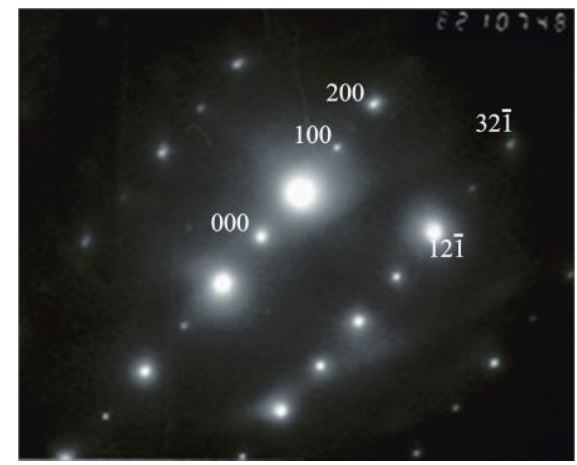

$\sigma$

Рис. 6. Микроструктура сплава $\mathrm{Fe}-\mathrm{Cr}-\mathrm{Al} \mathrm{c} 8$ мас. \% $\mathrm{Al}$ после термодиффузионного алитирования: $a$ - темнопольное изображение в сверхструктурном рефлексе 100 ; б - микродифракция, ось зоны [012] $\mathrm{B}_{2}$

На поверхности внешнего кожуха блока из листовой аустенитной стали $12 \mathrm{X} 18 \mathrm{H} 10 \mathrm{~T}$ в процессе алитирования формируется покрытие толщиной порядка $100-160$ мкм (рис. 7 б). Внешняя зона покрытия представляет собой упорядоченную по типу В2-фазу $(\mathrm{Fe}, \mathrm{Cr}, \mathrm{Ni}) \mathrm{Al}$ толщиной около 20 мкм, микротвердостью 765 HV 0,05, содержание алюминия в ней достигает 25 - 28 мас. \%. Далее следует тонкая прослойка, обогащённая никелем, которая представляет собой механическую смесь фаз $(\mathrm{Fe}, \mathrm{Ni}) \mathrm{Al}$ и $(\mathrm{Fe}, \mathrm{Ni})_{3} \mathrm{Al}$. Третья от поверхности зона состоит из $\alpha$-твёрдого раствора $\mathrm{Al}$ и $\mathrm{Ni}$ в ОЦК решётке $\mathrm{Fe}(\mathrm{Cr})$ и дисперсных частиц (Fe,Cr,Ni)Al. Толщина этой зоны 80 - 120 мкм, микротвердость - 345-390 HV 0,05. Концентрация алюминия в ней плавно снижается от 12 мас. \% вблизи внешней зоны до 4 мас. \% на границе со сплавом-основой. Естественно, что после образования покрытия жаростойкость нержавеющей стали существенно повышается: алитированный кожух при $1050{ }^{\circ} \mathrm{C} \sim$ в 3 раза, а при $1065{ }^{\circ} \mathrm{C}$ уже в 10 раз более жаростоек, чем неалитированный [3].

По результатам внедрения конического индентора методом компьютерного моделирования (методика описана ранее в работах [14-16]) были построены кривые сопротивления деформации сплавов с разным содержанием алюминия. Определённые значения коэффициентов $a$ и $b$ в функциональной зависимости напряжения от деформации для сплавов $\mathrm{Fe}-\mathrm{Cr}-\mathrm{Al}$ с разным содержанием алюминия представлены в табл. 3. Можно приблизительно оценить изменения значений временного сопротивления $\left(\sigma_{\mathrm{B}}\right)$ исследованных сплавов после алитирования по формуле [17]:

$$
\sigma_{\mathrm{B}}=a \cdot \varepsilon_{\text {кр. }}{ }^{b},
$$

где $\varepsilon_{\text {кр }}$ - критическая деформация, при которой начинается образование шейки (значение $\varepsilon_{\text {кр. }}$ принято равным показателю степени $b$ ). Согласно ГОСТ 12766.2 - 90 временное сопротивление для ленты Х15Ю5 толщиной 0,2 мм и более должно быть на уровне 736 МПа. Значения модуля нормальной упругости Е, определённые по участкам разгрузки на кривых «Р-h» при кинетическом нагружении образцов, с ростом концентрации алюминия в сплавах также увеличиваются, т.е. растет жесткость лент. 


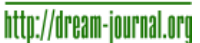
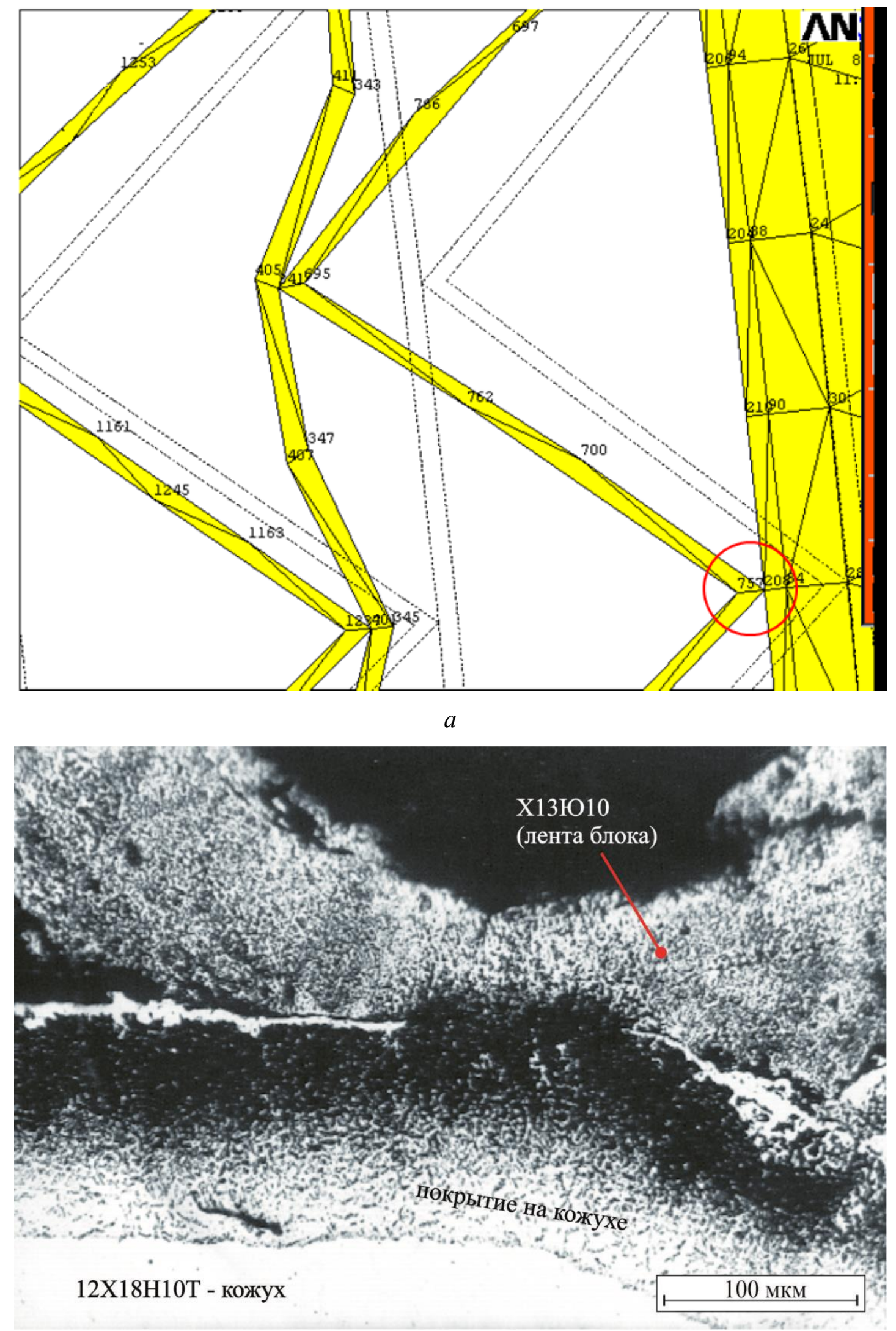

6

Рис. 7. Деформация ленты блока (a) при нагреве до $900{ }^{\circ} \mathrm{C}$ и микроструктура (б) узлов 84, 208, 757 (выделены красной окружностью). Пунктиром обозначено исходное положение ленты

Pugacheva N. B. et al. / Studying the structure and properties of the material of the nodes a honeycomb structure after diffusion aluminizing 
Дилатометрические испытания показали, что при алитировании разница в коэффициентах линейного теплового расширения сплава Х 20 Ю и стали $12 \mathrm{X} 18 \mathrm{H} 10 \mathrm{~T}$ уменьшается с 30 $\%$ до $10 \%$, в результате чего значительно повышается термостойкость сварного соединения ферритной ленты с обечайкой из аустенитной стали (табл. 4).

Таблица 3 - Значения коэффициентов $a$ и $b$ в определяющих соотношениях и механические свойства сплавов $\mathrm{Fe}-\mathrm{Cr}-\mathrm{Al}$

\begin{tabular}{|c|c|c|c|c|c|}
\hline $\begin{array}{c}\text { Содержание Al, } \\
\text { мас. \% }\end{array}$ & $a$, МПа & $b$ & $\sigma_{\text {в }, \text { MПа }}$ & HV 0,05, МПа & Е, ГПа \\
\hline 5 & 1019 & 0,61 & 753,8 & $3400-4000$ & 188 \\
\hline 10 & 1032 & 0,63 & 771,4 & 4200 & 222 \\
\hline 13 & 1057 & 0,63 & 790,1 & 5000 & 234 \\
\hline
\end{tabular}

Таблица 4 - Коэффициент линейного расширения исследованных образцов $(\alpha \times 106, \mathrm{~K}-1)$

\begin{tabular}{|c|c|c|c|c|}
\hline \multirow{2}{*}{$\begin{array}{c}\text { Температурный } \\
\text { интервал, }{ }^{\circ} \mathrm{C}\end{array}$} & \multicolumn{2}{|c|}{ 12X18H10T } & \multicolumn{2}{|c|}{$\mathrm{X} 15$ Ю5 } \\
\hline & $\begin{array}{c}\text { в исходном со- } \\
\text { стоянии } \\
\end{array}$ & $\begin{array}{c}\text { после алитиро- } \\
\text { вания } \\
\end{array}$ & $\begin{array}{c}\text { в исходном } \\
\text { состоянии } \\
\end{array}$ & $\begin{array}{c}\text { после алити- } \\
\text { рования }\end{array}$ \\
\hline $20-100$ & 17,5 & 14,9 & 14,0 & 11,4 \\
\hline 20-200 & 17,9 & 15,2 & 12,4 & 11,7 \\
\hline $20-300$ & 18,0 & 15,3 & 13,0 & 12,3 \\
\hline $20-400$ & 17,8 & 15,4 & 13,1 & 12,7 \\
\hline $20-500$ & 18,6 & 15,6 & 13,0 & 13,3 \\
\hline $20-600$ & 19,1 & 15,8 & 13,0 & 13,7 \\
\hline $20-700$ & 19,3 & 16,4 & 13,6 & 14,0 \\
\hline $20-800$ & 19,5 & 16,9 & 14,0 & 14,3 \\
\hline $20-900$ & 19,5 & 17,2 & 14,3 & 15,0 \\
\hline
\end{tabular}

Расчёты проведенные в программном обеспечении ANSYS показали, что при нагреве блока до температур, меньших $900{ }^{\circ} \mathrm{C}$, возникающие напряжения существенно ниже предела прочности и текучести сплава для всех элементов исследованной конструкции (рис. 8 и 9). 


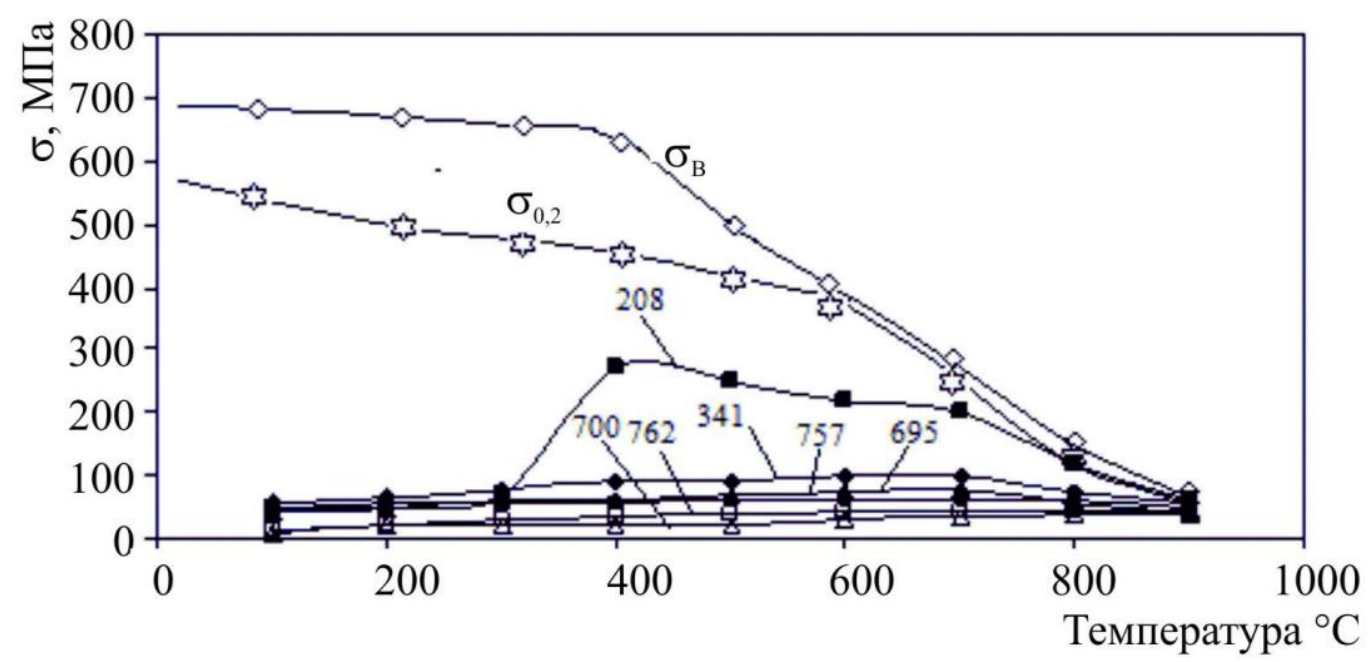

Рис. 8. Изменения значений интенсивности напряжений в узлах сетки гофрированной ленты из сплава $\mathrm{Fe}-\mathrm{Cr}-\mathrm{Al}$ при нагреве блока. Цифрами обозначены узлы в соответствии с рис. 3; $\sigma_{\mathrm{B}}$ и $\sigma_{0,2}-$ справочные значения для сплава X15Ю5 (табл. 1 )

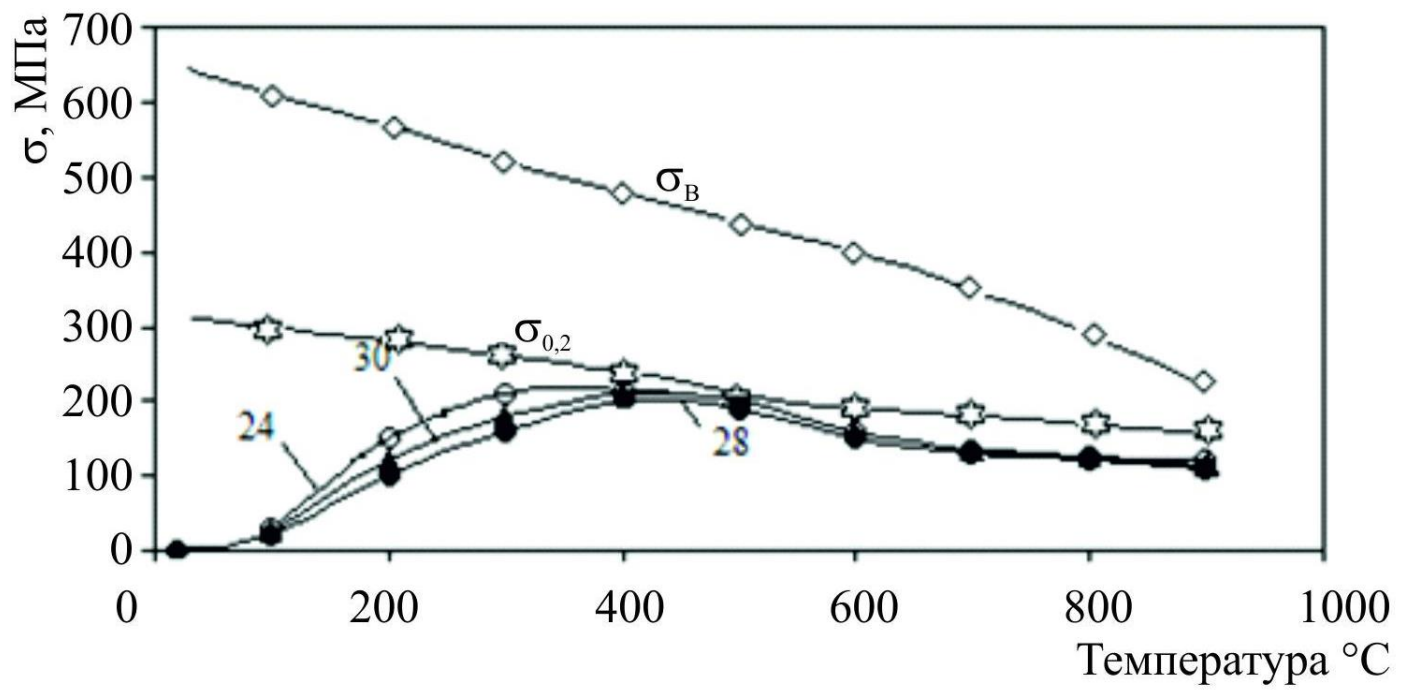

Рис. 9. Изменения значений интенсивности напряжений в узлах сетки верхнего слоя покрытия кожуха из стали $12 \mathrm{X} 18 \mathrm{H} 10 \mathrm{~T}$ при нагреве (нумерация узлов в соответствии с рис. 3 ); $\sigma_{\text {в и }}$ $\sigma_{0,2}-$ справочные значения для стали $12 \mathrm{X} 18 \mathrm{H} 10 \mathrm{~T}$

При температурах, близких к $900{ }^{\circ} \mathrm{C}$, происходит деформация плоской ленты (рис. 7 a и 10). На практике при многократной ХТО блоков по разным температурно-временным режимам деформация ленты не наблюдалась. В гофрированной ленте при нагреве преобладают растягивающие напряжения, а в прямой, как и в кожухе - сжимающие (рис. 10 a). На участке предполагаемого изгиба ленты между узлами 347 и 407 интенсивность напряжений не высока (рис. 10 б). 

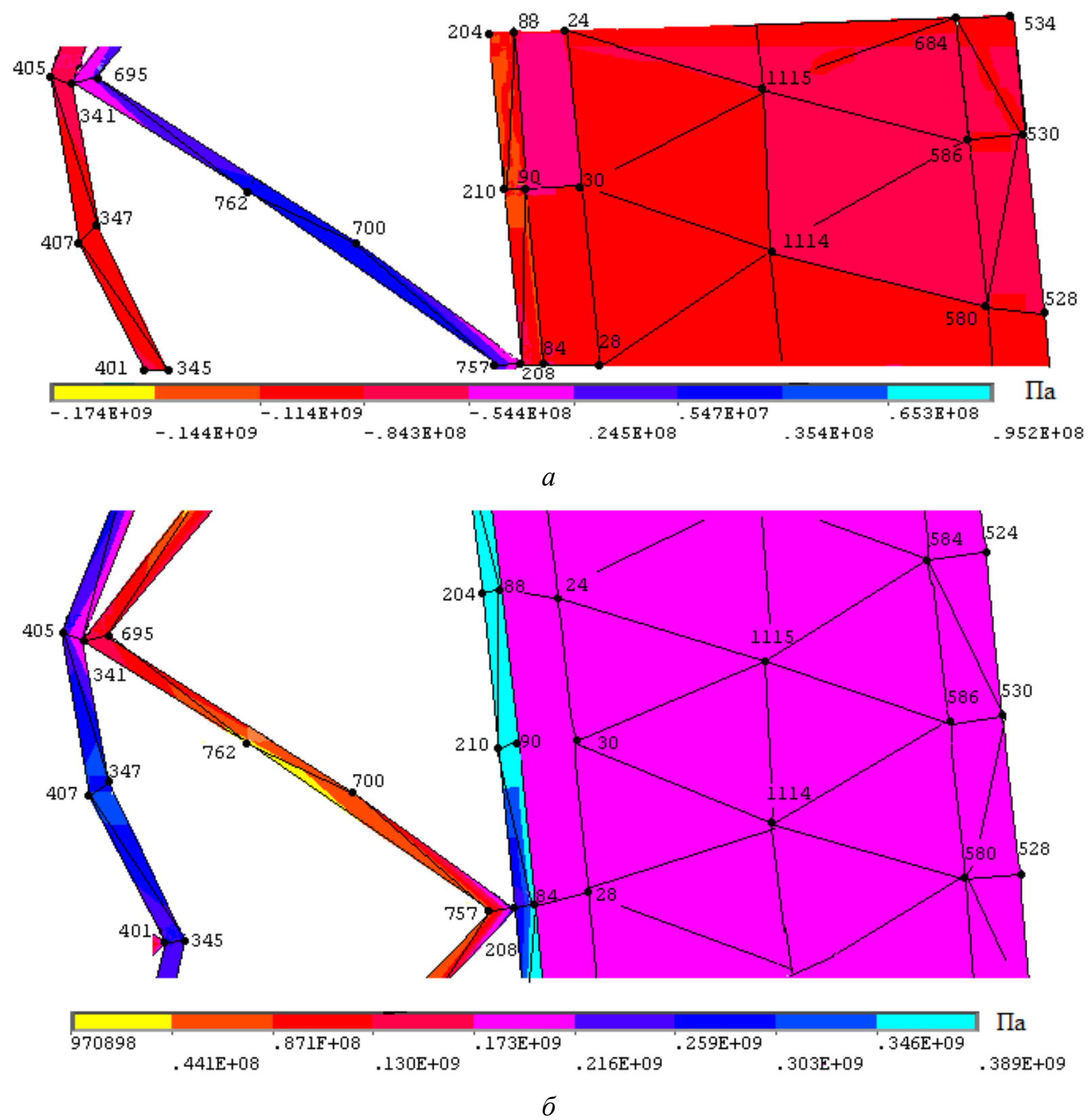

Рис. 10. Распределение гидростатических напряжений $(a)$ и интенсивности напряжений (б) в исследованных узлах блока при нагреве до $900{ }^{\circ} \mathrm{C}$

(нумерация узлов в соответствии с рис. 3)

Анализ результатов расчета показал, что при заданных условиях теплообмена стационарный режим нагрева достигается уже через 0,01 с. При этом максимальные значения напряжений возникают в самом начале процесса (от 0,01 до 0,2 c). Общая длительность рассчитанного процесса $(\tau)$ составила 7 с. После 0,5 с для большинства узлов значения напряжений становятся постоянными и при нагреве до температуры $600{ }^{\circ} \mathrm{C}$ расчетные значения напряжений в узлах конструкции существенно ниже предела текучести исследованных материалов (рис. 11). 


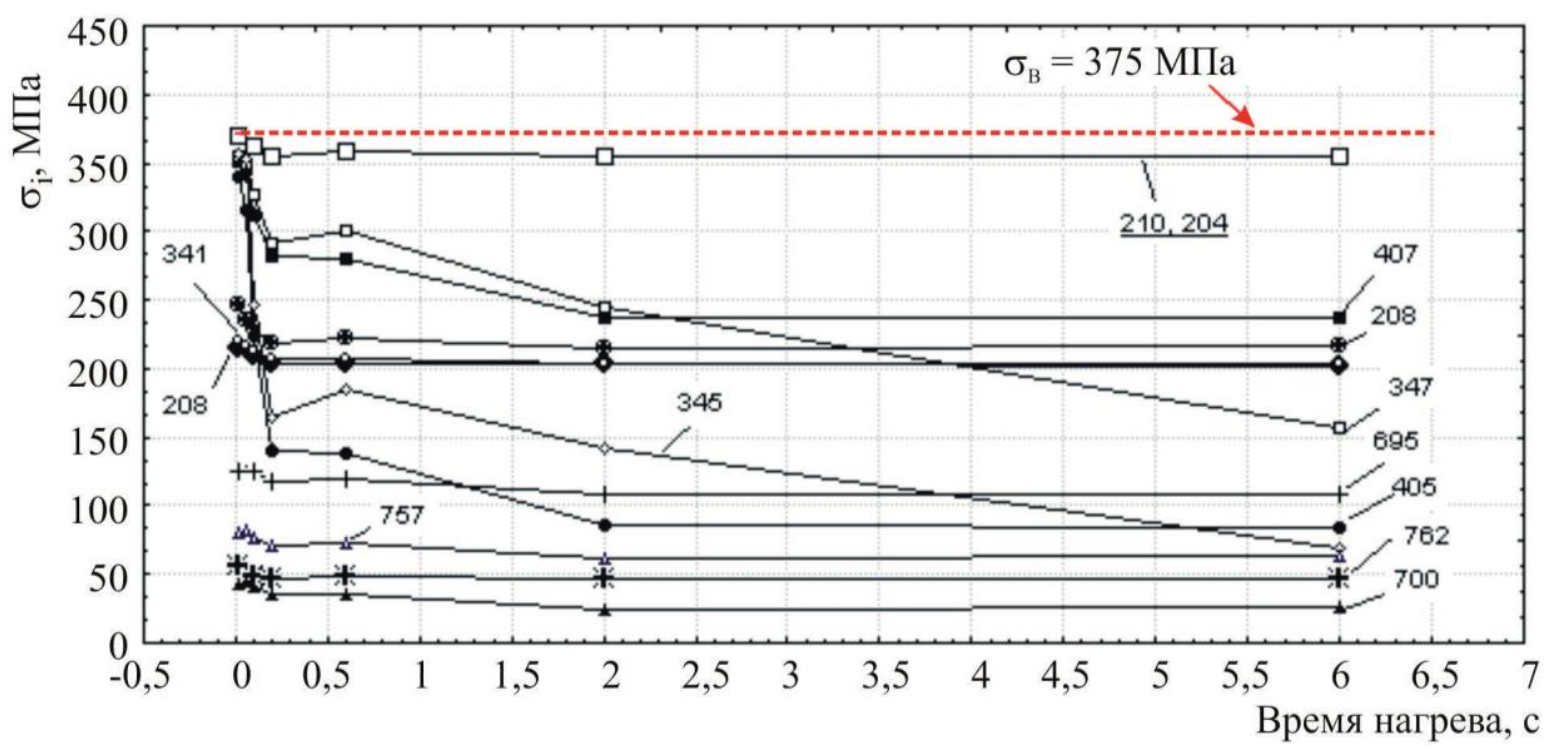

$a$

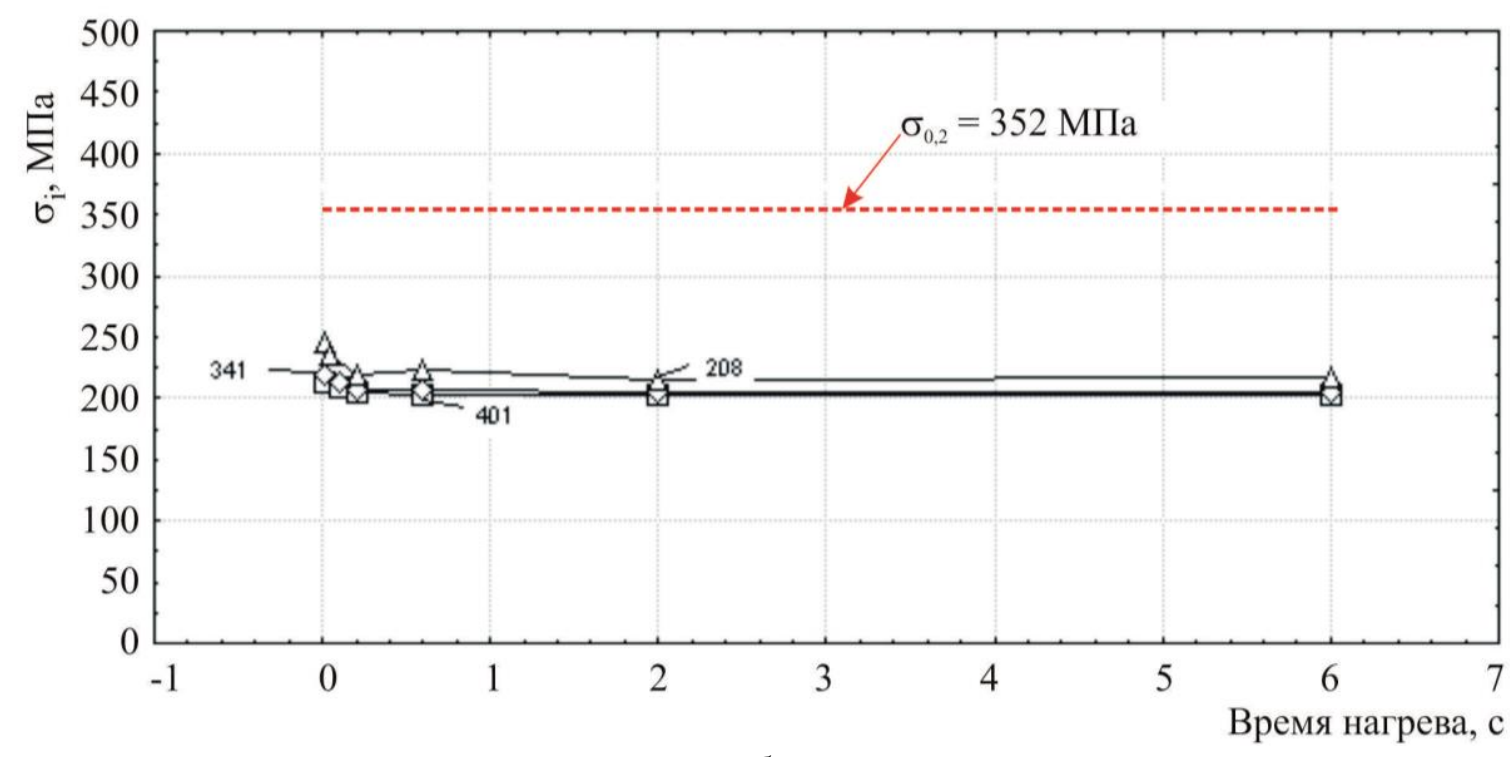

$\sigma$

Рис. 11. Изменение значений интенсивности напряжений в процессе нагрева при температуpe среды $600{ }^{\circ} \mathrm{C}: a-$ в узлах блока; $\sigma$ - в узлах сварки лент блока (нумерация узлов в соответствии с рис. 3) ); $\sigma_{\mathrm{B}}=390$ МПа и $\sigma_{0,2}=370$ МПа справочные данные для сплава Х15Ю5 при температуре $600{ }^{\circ} \mathrm{C}$ (табл. 1)

В узлах диффузионной сварки лент 208 и 341, являющихся наиболее важными элементами блока, расчётные значения напряжений при температурах выше $750{ }^{\circ} \mathrm{C}$ близки к значениям условного предела текучести (рис. 8). Однако в этих узлах преобладают сжимающие напряжения (рис. 10 ), что наиболее удачно для его эксплуатации. Значения напряжений для узлов, расположенных в элементах кожуха, значительно ниже, чем в ленте. Причем, возникающие напряжения практически одинаковы по всему сечению кожуха и являются сжимающими (рис. 10 a). Покрытие на кожухе имеет отличающиеся значения коэффициента линейного термического расширения, поэтому не следует исключать его растрескивание при быстром нагреве. Расчеты показали, что напряжения, возникающие при нагреве до $900{ }^{\circ} \mathrm{C}$ в узлах $24,1114,684,524,30,1115,586,530,28$, расположенных в покрытии на кожухе, имеют практически одинаковые значения (рис. 10 б). 
Для экспериментальной проверки прочности сцепления лент в сотовой конструкции были проведены испытания на термоциклирование: нагрев в течение 6 с до температур 900 ${ }^{\circ} \mathrm{C}$ и быстрое охлаждение на воздухе. При этом концы сваренных лент образцов (размеры 90х30 мм) разводили на расстояние 4 см и жестко закрепляли, создавая тем самым некоторую нагрузку для разделения лент. Ленты отделялись друг от друга только через 1000 циклов, что подтверждает прочность их сцепления.

\section{4. Заключение}

Экспериментально установлены особенности изменения микроструктуры тонкой ленты из сплава Х15Ю5 и кожуха из стали $12 \mathrm{X} 18 \mathrm{H} 10 \mathrm{~T}$ после термодиффузионного алитирования, а также структура и химический состав узлов сотовой конструкции. Алитирование по механизму низкой активности позволяет получать равномерное увеличение содержания алюминия по всей толщине ленты Х15Ю5, при этом концентрация хрома в ленте не изменяется, формируется новый материал Х15Ю8 или Х15Ю10. В исходном феррите происходит образование доменов B2-фазы (Fe, $\mathrm{Cr}) \mathrm{Al}$, объем которых увеличивается с ростом концентрации алюминия в ленте.

Гофрированная лента конструкции на участках контакта с плоской лентой после термодиффузионного алитирования прочно соединяется по механизму диффузионной сварки, образуя единый материал. Узлы сопряжения гофрированной ленты с поверхностью стального кожуха образуют градиентное сопряжение, в котором меняются не только химический и фазовый состав, но и теплофизические свойства.

Моделирование термонапряжённого состояния сотовой конструкции при нагреве показало, что возникающие напряжения в большинстве точек являются сжимающими, значения растягивающих напряжений в гофрированной ленте не превышают 34 МПа, максимальные напряжения формируются в покрытии на кожухе.

\section{Благодарность}

Работа выполнена в соответствии с планом Фундаментальных научных исследований государственных академий наук на 2016 - 2020 г. по теме ГР № 01201375907.

\section{Литература}

1. Наото Й. Влияние легирующих элементов на стойкость к окислению при высоких температурах фольги из ферритной нержавеющей стали, применяющейся в качестве носителя металлических катализаторов // Дзайре то Пуросэсу (Curr. Adv. Mater. and Proc.). - 1991. Vol. 4, no. 6. - C. 1772-1775.

2. Микио Й. Разработка фольги из термостойкой стали, выполняющую функцию металлического носителя // Дзайре то Поросэсу (Curr. Adv. Mater. and Proc.). - 1991. - Vol. 4, no. 6. - C. $1784-1787$.

3. Increase in thermal stability of metallic monolith supports for catalysts by gas-phase calorizing / S. V. Kositsyn, V. V. Korol'kov, V. I. Tesla, A. N. Vladimirov, N. B. Pugacheva // Kinetics and Catalysis. - 1998. - Vol. 39, iss. 5. - P. 649-654.

4. Корнилов И. И. Железные сплавы. Сплавы железо-хром-алюминий: в 2 т. - М.; Л. : Изд-во АН СССР, 1945. - 416 с.

5. Сплавы для нагревателей / Л. П. Жуков, И. М. Племянникова, М. Н. Миронова, Д. С. Баркая, Ю. В. Шумков. - М. : Металлургия, 1985. - 144 с.

6. Современные жаростойкие материалы: справ. изд. / под ред. С. Мровец, И. Вербера; пер. с польского под ред. С. Б. Масленкова. - М. : Металлургия, 1986. - 360 с.

7. Pugacheva N. B., Ekzemplyarova E. O., Zadvorkin S. M. Effect of aluminium on the structure and physical properties of $\mathrm{Fe}-\mathrm{Cr}-\mathrm{Al}$ alloys // Russian Metallurgy. - 2006. - No. 1. P. 61-68. - DOI: 10.1134/S0036029506010113.

Pugacheva N. B. et al. / Studying the structure and properties of the material of the nodes a honeycomb 
8. Oliver W. C., Phar G. M. An improved technique for determining hardness and elastic modulus using load and displacement sensing indentation experiments // Journals of Materials Research. - 1992. - Vol. 7, iss. 06. - P. 1564-1583. - DOI: 10.1557/JMR.1992.1564.

9. Головин Ю. Г. Определение комплекса механических свойств материалов в нанообъемах методами наноиндентирования / Ю. И. Головин, В. И. Иволгин, В.В.Коренков, Р. И. Рябко // Конденсированные среды и межфазные границы. - 2001. - Т. 3, № 2. C. $122-135$.

10. Булычев С. И., Алехин В. П. Определение предела текучести по фактической площади контакта сферического индентора при нано-, микро- и макроиндентировании // Деформация и разрушение материалов. - 2007. - № 1. - С. 30-37.

11. Гузанов Б. Н., Косицын С. В., Пугачева Н. Б. Упрочняющие защитные покрытий в машиностроении. - Екатеринбург : Изд-во УрО РАН, 2003. - 244 с.

12. Колачев Б. А., Ильин А. А., Дроздов П. Д. Состав, структура и механические свойства двойных интерметаллидов // Известия ВУЗов. Цветная металлургия. - 1997. - № 6. C. 41-52.

13. Pugacheva N. B. The structure and properties of alloys and coatings with an ordered $\beta$ - phase following heat treatment // Metal Science and Heat Treatment. - 2007. - Iss. 5. P. 240-247. - DOI: 10.1007/s11041-007-0043-4.

14. Resistance to deformation of structural constituents of a high-alloy brass / S. V. Smirnov, N. B. Pugacheva, A. V. Tropotov, A. N. Soloshenko // Physics of Metals and Metallography. 2001. - Vol. 91, no. 2. - P. 210-215.

15. Plastic deformation of a high-alloy brass / S. V. Smirnov, N. B. Pugacheva, A. N. Soloshenko, A. V. Tropotov // Physics of Metals and Metallography. - 2002. - Vol. 93, no. 6. - P. 584-593.

16. Микромеханика разрушения и деформации латуни / С. В. Смирнов, Н. Б. Пугачева, М. В. Мясникова, П. П. Матафонов, Т. В. Полковников // Физическая мезомеханика. - 2004. - № 7, ч. 1. - С. 165-168.

17. Колмогоров В. Л. Механика обработки металлов давлением. - М. : Металлургия. $688 \mathrm{c}$.

18. Ключ сталей. Изготовление и поставка : справочник / пер с нем. - М. : Интермет Инжиниринг, 2001. - 734 с.

19. Стали и сплавы. Марочник : справ. изд. / научная ред. В. Г. Сорокина, М. А. Гервасьева. - М. : Интермет Инжиниринг, 2003. - 608 с. 